\title{
Development of rose and crabapple compound beverage
}

\author{
Fan Dan-min ${ }^{1,2}$, Yang Zhi-long ${ }^{1,2}$ \\ ${ }^{1}$ Institute of Technolog, Lijiang Teachers College,Lijiang,China \\ ${ }^{2}$ Research Center for Plateau Characteristic Agriculture in Northwest Yunnan Province, Lijiang, China
}

\begin{abstract}
A nutrient-richness rose-crabapple compound beverage was developed using edible rose and crabapple as raw material, and the processing technology of compound beverage was also investigated. Fresh rose petals were mixed with sugar at the mass ratio of 1:1, maturing 3 months at room temperature. Then a unique-flavor rose liquor was extracted from the mature rose-sugar mixture, whereas the flavor crabapple extracts were extracted from 20 grams of crabapple in one liter purified water. The compound beverage processing parameters were identified to ensure the optimum rose beverage processing formula by sensory evaluation and orthogonal test.
\end{abstract}

\section{Introduction}

Rose (rosa rugosa thumb), also known as thorn rose, is a perennial evergreen or deciduous shrub of rose genus in Rosaceae ${ }^{[1]}$, with thick branches, and full of thorns on the epidermis of the stem section ${ }^{[2]}$. Rose cultivation has been in China for thousands of years and used as a spice plant endemic to China, whose petals are widely used in beauty, cosmetics, food, tea, wine, drugs, etc. [3] According to the analysis of pharmacological components, roses contain a lot of essential components for human body, such as volatile oil, phenylethyl alcohol, esters, nerol, red pigment, carotene, wax and so on. Among them, flavonoid glycosides, anthocyanins, and $\beta$-carotene have certain health and nutrition effects.

Plum-leaf crab (Malus prunifolia (Willd.) Borkh) is a special local product of Lijiang in Yunnan Province, with functions of appetizing, diuretic and anti-inflammatory. Plum-leaf crabs have abundant nutrients and is rich in vitamins, with the highest content of $\beta$-carotene ; edible plum-leaf crabs can supplement the trace elements needed by human body to promote health. The amino acid composition of plum-leaf crabs has higher content of aspartic acid and proline. Proline has the function and effect of brain health and brain protection, enhancing the effect of cellular respiration, while aspartic acid has anti-fatigue effect on human body. Calcium, protein, fat and other compositions are also very plentiful. In addition, plum-leaf crabs are effective in lowering blood pressure, strengthening stomach and digestion, lowering blood fat, softening blood vessels, fighting cancer and resisting oxidation ${ }^{[4-5]}$.

In recent years, the area of edible rose cultivation in Yunnan province has increased year by year, and the processed products of rose flowers are less, mainly concentrated on rose flower cake, rose candy, rose sauce and so on. In this study, roses and plum-leaf crabs were used as the main raw materials to study the compound beverage of rose and plum-leaf crab, which provided some theoretical reference for the production of rose compound products.

\section{Materials and methods}

\subsection{Materials and Instruments}

Roses (Dianhong) and plum-leaf crabs (dried fruit) sold in Lijiang City, Yunnan Province; Citric acid sold in Weifang Yingxuan Industrial Co., Ltd.; Sucrose and honey sold in the market; SC-DC-AS electronic balance bought from Nanjing Suce measurement Co., Ltd.; Handheld saccharometer-ATAGO PAL-2 purchased from Japan Atago; Stainless steel cookers; Induction cooker of Midea DS2105; Gauze sold in the market; Glass bottles sold in the market, etc.

\subsection{Experimental methods}

\subsubsection{Preparation of rose juice}

Rose (flower petals) $\rightarrow$ pretreatment $\rightarrow$ addition of white sugar $\rightarrow$ mixture $\rightarrow$ sealing $\rightarrow$ fermentation $\rightarrow$ extraction $\rightarrow$ filtration $\rightarrow$ rose flower juice

\subsubsection{Preparation of plum-leaf crab juice}

Plum-leaf crab $\rightarrow$ cleaning $\rightarrow$ extraction $\rightarrow$ filtration $\rightarrow$ clarification for standby

\subsubsection{Preparation of rose compound beverage}

\footnotetext{
* Corresponding author: Email address: fdm.2007@163.com
} 


\subsubsection{Process flow}

Rose juice

$\downarrow$

Blending (auxiliary materials) $\rightarrow$ homogenization $\rightarrow$ filling $\rightarrow$ sterilization $\rightarrow$ cooling $\rightarrow$ compound beverage

$\uparrow$

Plum-leaf crab juice

\subsection{Main operation points}

\subsubsection{Treatment of roses}

Edible roses (Dianhong) were selected and the petals were removed. The rose petals were cleaned up with water and dried out. The petals and white sugar were mixed and curlated at the ratio of $1: 1$, until the roses and white sugar were completely mixed. When the mixture became aubergine, it was sealed and fermented for more than 3 months, and rose sugar was obtained.

\subsubsection{Extraction of rose sugar}

Moderate rose sugar was weighed, added with a certain amount of citric acid and $1 \mathrm{~L}$ of water. And it was heated and stirred to make the rose sugar fully dissolved, filtered, made up to $1 \mathrm{~L}$, and then rose juice was got.

\subsubsection{Extraction of plum-leaf crabs}

Table 1 The quality evaluation standard of rose-plumleaf crab compound beverage (100 points)

\begin{tabular}{lll}
\hline Sensory index & Standard for evaluation & Score \\
\hline \multirow{3}{*}{ Color } & Presenting rose red, clear & $21-30$ points \\
& Pink, not clear enough & $11-20$ points \\
& Darker shade & $1-10$ points \\
Fragrance and & The fragrance of the rose is prominent, no smell & $31-40$ points \\
taste & The fragrance of the rose is not prominent, with & $20-30$ points \\
& obvious odor. & \\
& No fragrance, obvious odor & $1-19$ points \\
Appearance & Clear and bright, no precipitation & $21-30$ points \\
& Slightly turbid, with a small amount of suspended & $11-20$ points \\
& matter & \\
& The color is turbid, and the precipitation is excessive & $1-10$ points \\
\hline
\end{tabular}

Under the conditions of $200 \mathrm{~mL}$ plum-leaf crab juice, $8 \%$

\subsection{Design of experiments}

\subsubsection{Single factor experimental design of rose juice}

Under the conditions of $200 \mathrm{~mL}$ rose juice, $8 \%$ white granulated sugar, and $0.10 \%$ citric acid, the amount of rose juice was adjusted to $150 \mathrm{~mL}, 200 \mathrm{~mL}, 250 \mathrm{~mL}, 300$ $\mathrm{mL}$, and $350 \mathrm{~mL}$, respectively, to determine the effect of the amount of rose juice on the quality of the rose and plum-leaf crab compound beverage.

2.4.2 Single factor experimental design of plum-leaf crab juice
The non-rotted dried plum-leaf crabs were selected and weighed $20 \mathrm{~g}$, added $1 \mathrm{~L}$ of water, stirred and boiled for $30 \mathrm{~min}$, and filtered. The filtrate was taken and diluted to $1 \mathrm{~L}$, and plum-leaf crab juice was obtained.

\subsubsection{Blending}

$200 \mathrm{~mL}$ of plum-leaf crab juice was added to $300 \mathrm{~mL}$ of rose juice, and the mixture was added honey, white granulated sugar, and citric acid, and then mixed and filtered.

\subsubsection{Sterilization and filling}

After the rose and plum-leaf crab compound beverage was filled, it was sterilized in boiling water for 20-30 minutes, taken out, and cooled to obtain the finished product.

\subsubsection{Sensory evaluation of products}

The evaluation group for sensory evaluation of the products consisted of 10 food students $(5$ males and 5 females) ${ }^{[15]}$, and they scored separately in three aspects of color, fragrance and taste, and appearance. Total score of 100 points was used to evaluate, removing the highest score and the lowest score, and taking the average score as the final sensory score. The sensory scoring criteria are shown in Table 1. white granulated sugar, and $0.10 \%$ citric acid, the amount of rose juice was adjusted to $150 \mathrm{~mL}, 200 \mathrm{~mL}, 250 \mathrm{~mL}$, $300 \mathrm{~mL}$, and $350 \mathrm{~mL}$, respectively, to determine the effect of the amount of plum-leaf crab juice on the quality of the rose and plum-leaf crab compound beverage.

\subsubsection{Single factor experimental design of white granulated sugar}

Under the conditions of $300 \mathrm{~mL}$ rose juice, $200 \mathrm{~mL}$ plum-leaf crab juice, and $0.10 \%$ citric acid, the additive amount of white granulated sugar was adjusted to $5 \%, 6 \%$, $7 \%, 8 \%$, and $9 \%$, respectively, to determine the effect of the additive amount of white granulated sugar on the quality of the rose and plum-leaf crab compound beverage. 


\subsubsection{Single factor experimental design of citric acid addition}

Under the conditions of $300 \mathrm{~mL}$ rose juice, $200 \mathrm{~mL}$ plum-leaf crab juice, and $8 \%$ white granulated sugar, the additive amount of citric acid was adjusted to $0.0 \%$, $0.05 \%, 0.10 \%, 0.15 \%$, and $0.20 \%$, respectively, to determine the effect of the additive amount of citric acid on the quality of the rose and plum-leaf crab compound beverage.

\subsection{Product quality detection}

The content of soluble solids was determined by hand-held refractometer; the total acid content was determined by titration method referred to $\mathrm{GB} / \mathrm{T}$ 12456-2008 [16]; For the microbial index, the total bacterial number was determined by the method in GB 4789.2-2010 [17], the coliform was measured by the method in GB 4789.3-2010 ${ }^{[18]}$, and the pathogenic bacteria was measured by the method in GB 29921-2013 [19].

\section{Results and discussions}

\subsection{Effect of the addition of rose juice on the quality of beverage}

Table 2 Effect of the addition of rose juice on the quality of the beverage

\begin{tabular}{lc}
\hline Addition of rose juice/mL & Sensory score/points \\
\hline $1150 \mathrm{~mL}$ & 65 \\
$200 \mathrm{~mL}$ & 80 \\
$250 \mathrm{~mL}$ & 84 \\
$300 \mathrm{~mL}$ & 85 \\
$350 \mathrm{~mL}$ & 79 \\
\hline
\end{tabular}

According to the results of sensory evaluation in Table 2, the sensory score increases gradually with the increase of the additive amount of rose juice, and the highest score is obtained when the addition of rose juice is $300 \mathrm{~mL}$, with the best effect and moderate fragrance of rose. When the addition exceeds $300 \mathrm{~mL}$, the fragrance of rose is too strong, and the bitterness is also increased, which affects the overall quality of the compound beverage.

\subsection{Effect of the addition of plum-leaf crab juice on the quality of beverage}

Table 3 Effect of the addition of plum-leaf crab juice on the quality of the beverage

\begin{tabular}{lc}
\hline Addition of plum-leaf crab juice $/ \mathrm{mL}$ & Sen \\
\hline $1150 \mathrm{~mL}$ & 78 \\
$200 \mathrm{~mL}$ & 81 \\
$250 \mathrm{~mL}$ & 85 \\
$300 \mathrm{~mL}$ & 84 \\
$350 \mathrm{~mL}$ & 80
\end{tabular}

From the sensory evaluation results in Table 3 , it can be seen that with the increase of the additive amount of plum-leaf crab juice, the sensory score is gradually increased. The highest score is obtained when the additive amount of plum-leaf crab juice is $250 \mathrm{~mL}$, with the best effect and moderate fragrance of rose and plum-leaf crab compound beverage. When the addition exceeds $250 \mathrm{~mL}$,

the sour taste also increases, affecting the quality of the compound beverage, so $200 \mathrm{~mL}, 250 \mathrm{~mL}$, and $300 \mathrm{~mL}$ are introduced for orthogonal experiment.

\subsection{Effect of the addition of white granulated sugar on the quality of beverage}

Table 4 Effect of the addition of white granulated sugar on the quality of the beverage

\begin{tabular}{lc}
\hline Addition of white granulated sugar $/ \%$ & Sensory score/points \\
\hline $5 \%$ & 70 \\
$6 \%$ & 84 \\
$7 \%$ & 87 \\
$8 \%$ & 85 \\
$9 \%$ & 83 \\
\hline
\end{tabular}

As can been seen from the results of sensory evaluation in Table 4, the highest score is obtained when the addition of white granulated sugar is $7 \%$, with the best ratio of sweet and sour and the most harmonious taste of rose and plum-leaf crab compound beverage. When the addition amount exceeds $7 \%$, the sweetness increases with poorer taste, so $6 \%, 7 \%$, and $8 \%$ are introduced for orthogonal experiments.

3.4 Effect of the addition of citric acid on the quality of beverage 
Table 5 Effect of the addition of white granulated sugar on the quality of beverage

\begin{tabular}{lc}
\hline Addition of citric acid $/ \%$ & Sensory score/points \\
\hline $0.0 \%$ & 68 \\
$0.05 \%$ & 79 \\
$0.10 \%$ & 82 \\
$0.15 \%$ & 81 \\
$0.2 \%$ & 77 \\
\hline
\end{tabular}

According to the results of sensory evaluation in Table 5, the highest score is obtained when the addition of citric acid is $0.10 \%$, with the best ratio of sweet and sour and the most harmonious taste of rose and plum-leaf crab compound beverage. When the addition reaches $7 \%$ or more, the sweetness increases with poorer taste, so $0.05 \%$, $0.1 \%$, and $0.15 \%$ are introduced for orthogonal

\subsection{Formula optimization of rose beverage}

In the orthogonal experiment design at the level of $\mathrm{L}_{9}\left(3^{4}\right)$, four factors and three levels of experiments were carried out, and the orthogonal experiment results are presented in Table 7. experiments.

Table 6 Factors and levels of orthogonal experiment

\begin{tabular}{|c|c|c|c|c|}
\hline Levels & Factors & & & \\
\hline Level & A Rose juice (mL) & $\begin{array}{l}\text { B Plum-leaf crab } \\
\text { juice }(\mathrm{mL})\end{array}$ & $\begin{array}{l}\text { C White granulated } \\
\text { sugar }(\%)\end{array}$ & D Citric acid (\%) \\
\hline 1 & 200 & 200 & 6 & 0.05 \\
\hline 2 & 250 & 250 & 7 & 0.10 \\
\hline 3 & 300 & 300 & 8 & 0.15 \\
\hline
\end{tabular}

Table 7 Orthogonal experiment results of optimal formula

\begin{tabular}{lccccc}
\hline Experiment NO. A & B & C & D & Score \\
\hline 1 & 1 & 1 & 1 & 1 & 76 \\
2 & 1 & 2 & 2 & 2 & 80 \\
3 & 1 & 3 & 3 & 3 & 82 \\
4 & 2 & 1 & 2 & 3 & 82 \\
5 & 2 & 2 & 3 & 1 & 78 \\
6 & 2 & 3 & 1 & 2 & 83 \\
7 & 3 & 1 & 3 & 2 & 85 \\
8 & 3 & 2 & 1 & 3 & 83 \\
9 & 3 & 3 & 2 & 1 & 78 \\
K1 & 238 & 243 & 242 & 232 & \\
K2 & 243 & 245 & 240 & 248 & \\
K3 & 246 & 243 & 245 & 247 & \\
R & 8 & 2 & 5 & 16 & \\
\hline
\end{tabular}

It can be seen from Table 7 that the main order of factors affecting product quality is: citric acid content $>$ rose juice content $>$ white granulated sugar content $>$ plum-leaf crab juice content. The best combination is $\mathrm{A}_{3} \mathrm{~B}_{1} \mathrm{C}_{3} \mathrm{D}_{2}$, which is the best formula. Therefore, the best formula is $300 \mathrm{~mL}$ of rose juice, $200 \mathrm{~mL}$ of plum-leaf crab juice, $8 \%$ of white granulated sugar, $0.10 \%$ of citric acid, and gets 85 points through the sensory evaluation.

\section{Product quality standards}

\subsection{Sensory Indexes}

Color: reddish brown, uniform overall; Fragrance and taste: pure fruit flavor, rich fragrance of rose, sweet and sour, slightly astringent; Appearance: clear and transparent, no suspension and impurities.

\subsection{Physical and chemical indexes}

The soluble solid content is $10 \%$ and the total acid content is $0.25 \%$.

\subsection{Microbial indexes}


Table 8 The measurement results of microbial indexes of beverage

\begin{tabular}{lc}
\hline Items & Indexes \\
\hline Total bacterial number, cuf/g & $<80$ \\
Coliform, MPN/100g & $<2$ \\
Pathogenic bacteria & Not detected \\
\hline
\end{tabular}

\section{Conclusions}

The optimal formula of the rose and plum-leaf crab compound beverage was obtained through the orthogonal experiment results: It was $300 \mathrm{~mL}$ rose juice, $200 \mathrm{~mL}$ plum-leaf crab juice, $8 \%$ of white granulated sugar, $0.10 \%$ of citric acid, $0.8 \%$ of honey, and $1 \mathrm{~g}$ licorice. The rose and plum-leaf crab compound beverage produced according to this formula has a unique fragrance of rose, rich floral fragrance, and the color is clear and bright, with a refreshing taste.

\section{Acknowledgment}

Supported by Science and Technology Plan Project of Yunnan Science and Technology Department (Grant No: 2018FD101)

\section{References}

1. Luzhencheng. Extraction technology of rose polyphenols and pigments and anti-aging effect of polyphenols [D]. Guangzhou: South China Normal University, 2006.

2. $\mathrm{Hu}$ Xiaoyan, Shen Caihong, Ao Zonghua, et al. Advances in research on active components of rose and rose wine [J]. Brewing technology, 2014, 11:68-72.

3. Yang Xinzheng, Yang De, Zhang Yuehua, et al. The value and development prospect of roses [J]. Xinjiang Agricultural Science, 2004, 41 (2): 110-112.

4. Saxena R C, Nath R, Palit G, et al. Effect of calophyllolide, a nonsteroidal anti-inflammatory agent,on capillary permeability[J].Plan taedica,1982,44(4): 246-248.

5. CHEN H X,ZHANG M,XIE B J.Components and antioxidant activity of polysaccharide conjugate from green tea[J].Food Chemistry,2005, 90(1/2): $17-21$. 